\title{
HDL \& LDL Status in Untreated Newly Detected Type 2 Diabetic Patients
}

\author{
Abu Tarek lqbal ${ }^{1^{*}}$ \\ $M$ Jalal Uddin² \\ Md Salehuddin ${ }^{3}$ \\ Hasan Murad ${ }^{4}$ \\ 'Department of Medicine \\ Chattagram Maa-O-Shishu Hospital Medical College \\ Chittagong, Bangladesh. \\ ${ }^{2}$ Department of Community Medicine \\ Chattagram Maa-O-Shishu Hospital Medical College \\ Chittagong, Bangladesh. \\ ${ }^{3}$ Department of Cardiology \\ Barisal Medical College, Bangladesh. \\ ${ }^{4}$ Department of Cardiology \\ University of Science \& Technology Chittagong (USTC) \\ Chittagong, Bangladesh.
}

\begin{abstract}
Objective: The study was conducted with a view to find out HDL \& LDL status in newly detected untreated Type II diabetic patients. Methods: Study was carried out on 116 (66 male \& 50 female) newly diagnosed untreated type 2 diabetes patients aged 40 - 65 years and were selected randomly for study. Fifty (25 male \& 25 female) non diabetic subjects aged 40 - 65 years were randomly selected as control. Results: LDL - $\mathrm{C}$ was significantly higher $(\mathrm{P}<.0001)$ and HDL $-\mathrm{C}$ was significantly lower $(<.0001)$ in study group in comparison to control group.Conclusion: Dyslipidemia is commonly found in type - 2 diabetic patients. It is a risk factor for microvascular complications. So it should be controlled effectively.
\end{abstract}

Key words: Diabetes Mellitus; Type-2 DM; HDL; LDL.

\section{INTRODUCTION}

Type-2 diabetes is often associated with dyslipidaemia. Type-2 diabetes is frequently associated with reduced concentration of HDL and increased concentration of $\mathrm{LDL}^{1-5}$. They are at risk of coronary artery \&peripheral vascular and cerebro vascular disease due to atheresclerosis and is a major cause of morbidity and mortality ${ }^{6}$. The Prevalence is 2 percent $^{7}$.

So it is reasonable to study HDL and LDL status in type-2 diabetes, when morbidity and mortality from diabetes and its complication is rapidly increasing day by day. WHO describes above problems as global epidemic.

Current diagnostic value of LDL \& HDL cholesterol.

\begin{tabular}{lrl} 
Lipid panel & Range $(\mathbf{m g} / \mathbf{d l})$ & Interpretation \\
\multirow{2}{*}{ LDL } & $<100$ & Optimum \\
& $100-129$ & Near or above optimum \\
$130-159$ & Border line high \\
$160-189$ & High \\
& $>190$ & Very high \\
HDL & $<40$ & Low \\
& $\geq 60$ & High
\end{tabular}


Aims \& Objectives

To measure HDL \& LDL level in newly diagnosed untreated type 2 diabetics.

\section{Place of Study}

At BIRDEM, Dhaka during the period of January to December 2003 (1 year).

\section{Study Population}

Study was carried out on 116 (66 male \& 50 female) newly diagnosed untreated type 2 diabetes patients aged $40-65$ years and were selected randomly for study. Fifty (25 male \& 25 female) non diabetic subjects aged 40 - 65 years were randomly selected as control.

\section{MATERIALS AND METHODS}

Clinical information relating to the diabetic subjects was obtained by detailed medical history and clinical examination at outpatient department of BIRDEM.

\section{Inclusion criteria:}

1) Newly detected type-II DM not receiving lipid lowering agents

\section{Exclusion criteria:}

1) Type II Diabetic who are on lipid lowering agents

2) Type II Diabetic who has other co-morbidity eg CKD, IHD etc

\section{Collection of Blood Sample}

Fasting blood sample was drawn from the antecubital vein with all aseptic precaution for the measurement of fasting serum total cholesterol, TG, HDL, LDL. Blood for plasma glucose was collected 2 hours after breakfast in all patients and controls serum glucose, TG, Total cholesterol serum high density lipoprotein were measured by auto analyzer and LDL was measured by formula :

LDL cholesterol $=$ Total cholesterol $-[(\mathrm{TG} / 5)+\mathrm{HDL}]$.

\section{RESULTS}

\section{a. Basic characteristics}

Total 65 diabetic patients. 34 (52\%) male and 31 (48\%) female with a mean age $50.51 \pm 7.85$ yearsTotal 50 control subjects, 25 $(50 \%)$ male \& 25 (50\%) female. Mean age $51.82 \pm 8.13$ years.
Table 1 : Comparison of anthropometric data between control \& Diabetic group

\begin{tabular}{lrrc} 
Parameters & Control $\mathbf{n}=\mathbf{5 0}$ & Diabetic $\mathbf{n}=\mathbf{6 5}$ & P value \\
Age (years) & $51.82 \pm 8.13$ & $50.51 \pm 7.85$ & .385 \\
Weight $(\mathrm{KG})$ & $56.36 \pm 5.34$ & $59.16 \pm 8.79$ & .045 \\
Height $(\mathrm{cm})$ & $159.14 \pm 7.28$ & $156.55 \pm 7.85$ & .073 \\
BMI & $22.25 \pm 1.5$ & $24.43 \pm 2.4$ & .001 \\
\hline
\end{tabular}

\section{b. Biochemical characteristics :}

Two hours post prandial blood glucose level and LDL, HDL are significantly higher among the diabetic group.

Table 2 : Biochemical parameters between control and diabetic group.

$\begin{array}{lrrc}\text { Parameters } & \text { Control } \mathbf{n}=\mathbf{5 0} & \text { Diabetic } \mathbf{n}=\mathbf{6 5} & \text { P value } \\ \text { Blood glucose (2HPP) } & 7.03 \pm 0.41 & 17.12 \pm 2.38 & <.001 \\ \text { LDL (Fasting) } & 105.17 \pm 27.09 & 164.75 \pm 25.30 & <.001 \\ \text { HDL (Fasting) } & 42.20 \pm 7.43 & 37.82 \pm 4.27 & <.001\end{array}$

Unpaired $t$ test was used in all cases.

\section{DISCUSSION}

Present study showed significant difference between case (Diabetic) and control group regarding different parameters like blood glucose level, LDL and HDL. In our study showed significantly higher LDL and lower $\mathrm{HDL}^{8-13}$. The finding of our study is consistent with the findings of them who found significantly higher concentration of LDL and low HDL $(\mathrm{P}>0.5)^{13}$.

\section{CONCLUSION}

Dyslipidemia is commonly found in type - 2 diabetic patients. It is a risk factor for microvascular complications. So it should be controlled effectively.

\section{DISCLOSURE}

All the authors declared no competing interest. 


\section{REFERENCES}

1. Uusitupa M, sitonenO, pyroralaK, Aroa, Herslo k, penttila I \& vatilainer E. the relationship of cordiovascular risk factors to the prevaleace coronary heart disease in newly diagnosed type II diabetis. Diabetology. 1985; 28: 653-659.

2. Falko JM, parr JH, Sinpson NR \&wynn v Wpoproteis analysis in varying degrees of glucose tolerance. Comparisonbetween noninsulindependend diabetics, inpaired glucose tolerance and control populations.

3. Kerredy AL, lappis TRJ, lavery TD, Haddes DR, weaver JA \& Montgomery DAD. Relation of high-density lipoprotein cholesterol concentration to type of diabates and its control. Br Med J. 1978; 2: 1191-1194.

4. Schonfeld G, Birze C, Miller JP, Kessler G \&santiago J. Apolipoproteis B levels and altered lipoprotein composition in diabetes. Diabetes. 1974; 23: 827-834.

5. Davidson MB, coulstonAM, Herman W, Ipp E, Jovanovic L, Lebovitz HE, Levin SR, editors. American. Diabetic Association: clinical practice Recommendations Diatetes care. 2003; 26(suppl 1): 55-520.

6. Garcia MJ, Namara PMM, Gordon T \&Kannell WB. Morbity and mortality in diabetics in the framingham population: sixteen years follow-up study. Diabetics. 1974; 23: 105-111.

7. Foster DW. Diabetesmellitas. Harrison's principles of Internal Medicine Mc-Graw Hill company, USA. 1998;2(14):2061-2062.

8. Brines ER, Mao SJT, Palumbo PJ, Fallon WM. Analysis of plasma lipids and apolipoproteins in insulin dpendend and noninsulin diabetes. Metabolism. 1984; 133: 42-49.

9. Dunn FL, Raskin p, Bilheriner DW \& Grundy SM. the effect of diabetic control in very low density lipoproteins triglyceride metabolism in patients with type II diabetes mellitas and marked hypertriglyceridemea. Metabolism. 1984; 33; 117-123.

10. TaskinenMr, Beltz WF, Harper I, Fields RM, Schonfeld G. Effects of NIDDM on very low density lipoprotein triglyceride and apolipoprotin B metabolism: stady before and after sultomylurea therapy Diabetes. 1986; 35: 1268-1277.

11. Mahtab H, Khatoon M, Rahnaen\&Banik NG lipoprotein pattern in diabetics of Banglades Med Res counc Bull. 1985; 11: 75-80.

12. Uusitupa M, Siitionen O, voutilainen E, Aro A, Hersio K. Serum lipids and lipoproteins in newly diagnosed non-insulin dependend (type II) diabetic patients with special reference to factors influencing HDL- cholesterol and triglycerides. Diabetes care. 1986; 17-22.

13. Uddin FM \&Miah AK. Lipid profile and its relation to fasting insulin level in non-insulin dependend diabetes mellitus (NIDDM). Bangladesh Med Res Counc Bull. 1995; 21:64-72. 